10.12957/demetra.2013.6648

\title{
A comida boa para pensar: sobre práticas, gostos e sistemas alimentares a partir de um olhar socioantropológico
}

\section{Food for thought: on practices, tastes and food systems from a social anthropological approach}

Maria Eunice Maciel'

Helisa Canfield de Castro'

1 Programa de Pós-graduação em Antropologia Social, Departamento de Antropologia, Instituto de Filosofia e Ciências Humanas. Universidade Federal do Rio Grande do Sul

Correspondência / Correspondence Helisa Canfield de Castro

E-mail: helisa_nut@hotmail.com

\section{Resumo}

A presente comunicação situa-se no campo de estudos da antropologia da alimentação e pretende discorrer sobre aspectos do ato alimentar sob o ponto de vista da cultura. Entendida como um campo aglutinador, a antropologia tem contribuído para a reflexão e a compreensão do fenômeno da alimentação incorporando nas análises representações, crenças, conhecimentos e práticas que são herdados e/ou aprendidos e que são compartilhados pelos indivíduos de uma dada cultura ou de um grupo social determinado. Buscaremos levantar algumas considerações sobre a formação do gosto alimentar enquanto mobilizador de significados e demarcador de identidades. Trataremos sobre a noção de sistema alimentar como uma proposta ampla capaz de aproximar diferentes disciplinas na apreensão do fenômeno enquanto dotado de complexidade. A partir de uma perspectiva sistêmica, é possível apreender as dinâmicas envolvidas na contemporaneidade em que há evidente convivência de uma heterogeneidade sociocultural.

Palavras-chave: Comida. Antropologia. Sistemas Alimentares.

\section{Abstract}

This communication is situated in the field of food anthropology and aims to discuss aspects of the act of eating from the cultural point of view. The research will raise some practical considerations about cooking or eating while mobilizing the marking of meanings and identities. Understood as a unifying 
field of study on food culture, anthropology has contributed to the reflection and understanding of the food phenomenon in analyzes that incorporate representations, beliefs, knowledge and practices that are inherited and/or learned and that are shared by individuals of a given culture or a particular social group. We will approach the notion of food system as a broad proposal capable of bringing different disciplines into an understanding of the food phenomenon as endowed with complexity and able to grasp the dynamics involved in contemporary living, where there is a clear cultural heterogeneity.

Key words: Food. Anthropology. Food Systems.

\section{Um fenômeno biocultural}

O antropólogo francês Claude Lévi-Strauss, ${ }^{1}$ em sua obra Mitológicas, recorreu à cozinha e ao preparo dos alimentos para estudar diversos mitos indígenas. Mais do que isso, Lévi-Strauss nos demonstrou que os alimentos podem ser utilizados quando se busca entender melhor aquilo que nos faz humanos. Assim, parafraseando o autor com relação aos mitos - que são bons para pensar -, trazemos a ideia de que o mesmo fenômeno ocorre com a comida: essas substâncias compostas por nutrientes e simbolismos são boas para comer e igualmente servem para pensar a realidade que nos cerca.

Lévi-Strauss nos instiga a pensar a comida a partir de sua função semiótica e comunicativa. Para ele, a cozinha é uma linguagem, uma forma de comunicação, um código complexo que permite compreender os mecanismos da sociedade à qual pertence, da qual emerge e que lhe dá sentido. ${ }^{2}$ Para além de uma pura redução que o situa como resposta a necessidades fisiológicas, o ato alimentar deve ser compreendido como um ato social que incorpora múltiplas dimensões do indivíduo.

A presente comunicação situa-se no campo de estudos da antropologia da alimentação, entendida, em concordância com Contreras \& Garcia, ${ }^{3}$ como um campo de estudos aglutinador sobre o conjunto de representações, crenças, conhecimentos e práticas herdados e/ou aprendidos que estão associados à alimentação e que são compartilhados pelos indivíduos de uma dada cultura ou de um grupo social determinado. Nosso esforço argumentativo num primeiro momento será no sentido de trazer ao debate reflexões sobre a comida e o comer enquanto condicionados pelas culturas e entendidos como relações dinâmicas; aspectos que acreditamos importantes na medida em que iluminam e qualificam as questões em torno da alimentação. 
Na segunda parte buscaremos levantar algumas considerações sobre o gosto e a preferência por certo alimentos, explorando como tais definições e decisões são multifacetadas, mobilizando significados e demarcando identidades - o que é transparecido quando falamos em gastronomia brasileira, gastronomia francesa, gastronomia italiana. Assim o gosto, longe de ser uma resposta inata e individual, estaria inserido num contexto, sendo expresso também no nível social.

Por fim trataremos sobre a noção de "sistema alimentar", ${ }_{4}^{4}$ cujo enfoque, inicialmente tratado pelo sociólogo francês Jean-Pierre Poulain, parece ser interessante quando se pretende articular os vários campos que estudam a alimentação num esforço interdisciplinar de caracterizá-la a partir da agregação dos diferentes níveis ou estágios pelos quais o homem tem convivido com o alimento.

A alimentação humana tem características muito particulares. Quando refletimos profundamente, percebemos sua abrangência no sentido de unir de forma inequívoca aspectos biológicos e fisiológicos a aspectos culturais. Sendo um fenômeno biocultural, seu estudo interessa a uma gama muito variada de pesquisadores com os mais diversos enfoques teóricos e metodológicos. Talvez a maior contribuição das ciências humanas e sociais para o fenômeno da alimentação humana é a de lhe atribuir significado. Nessa perspectiva nenhum alimento está livre das associações culturais e, sendo parte de um sistema cultural, a comida e seus contextos são repletos de símbolos, sentidos e classificações. Compreender as práticas ligadas à alimentação enquanto ação simbólica, a qual nos possibilita o acesso a outras dimensões da vida, a outros planos (social, político, econômico, psicológico), pode ser pensado como foco das análises antropológicas. Concordamos com Fischler, ${ }^{5}$ para quem o homem "come significados" e partilha com seus pares uma infinidade de representações no ato de comer. Nas palavras do autor, "o homem nutre-se de nutrientes, mas também de imaginários que são partilhados socialmente"(p.20) ${ }^{5}$ Se, por um lado, existe o valor nutritivo do alimento e todo um repertório de elementos que o caracterizam do ponto de vista biológico - proteínas, carboidratos, vitaminas -, há, por outro, um valor simbólico, um sentido simbólico, no ato alimentar que complexifica a questão, pois requer uma abordagem compreensiva.

Assim é que existe uma série de alimentos dispostos na natureza, mas dentre esses apenas alguns são considerados comida. Esta demarcação será configurada pelas culturas de acordo com processos históricos e dinâmicas sociais específicas. Nessa lógica a comida pode ser entendida como o alimento que carrega em si as dimensões de uma cultura, a qual imprime suas particularidades quanto ao que será comestível, em que ocasião e com quais pessoas. ${ }^{2}$ Embora o homem necessite de alimento de forma constante para manter-se vivo e, portanto, estaria potencialmente apto a comer de tudo, assim não o faz. Sua alimentação está baseada em escolhas que, compartilhadas socialmente, comporão uma estrutura alimentar assentada em regras, classificações, proibições. ${ }^{2}$ 
Mary Douglas atenta para o simbolismo dos processos classificatórios. Em termos alimentares, cada cultura possui um sistema classificatório que aponta o que é comestível ou não, em que circunstâncias, em companhia de quem. Tais processos também nos prescrevem ou interditam determinados comportamentos. Em outras palavras, as coisas são ordenadas de maneira diferente de acordo com cada esquema cultural. ${ }^{6}$ Assim, o que é definido como comestível em uma dada cultura pode não ser em outras. Um exemplo clássico é o cachorro, que, para nós, ocidentais, é considerado um animal de estimação, mas em alguns países asiáticos compõe parte de uma refeição ordinária.

É nessa perspectiva, de explorar a alimentação não apenas considerando sua função biológica, mas também sua inserção numa dada cultura ou sociedade, marcada temporal e espacialmente, que a antropologia da alimentação estabelece suas reflexões. O que propomos, nesse sentido, é a necessidade de um diálogo entre os campos capaz de formatar uma compreensão holística, não hierarquizada em termos explicativos, mas sim que enfatize a complementaridade do adjetivo "biocultural" que marca o ato alimentar.

\section{0 gosto que se discute}

Embora alguns pesquisadores concebam o gosto como algo inato, a princípio ligado ao domínio fisiológico, diferentes autores defendem que o gosto é construído social e culturalmente, articulando experiências individuais e coletivas.

O tema do gosto alimentar começou a ser explorado no contexto das sociedades de corte europeias como referência ao "bom gosto" como meio de distinção social. Flandrin nos faz pensar, ao historicizar o "gosto", que este se modifica no tempo, no espaço e para uma mesma pessoa. Para o historiador, durante a passagem do século XVIII ao XIX, desenvolveu-se uma concepção da alimentação distinta do conceito de nutrição. Assim a alimentação estaria atrelada ao prazer à mesa e às sensações do paladar, mais do que a preocupações estritamente dietéticas.

Bourdieu ${ }^{8}$ bem nos lembra que o gosto alimentar seria resultado de uma construção social por meio da qual se formam estratégias de distinção social. Distinções estas que expressarão diferentes estilos de vida e posições hierárquicas numa estrutura de classes. Analisando a variedade das práticas culturais entre os grupos sociais, Bourdieu afirma que o gosto cultural e os estilos de vida remetem a maneiras de se relacionar com as práticas dos sujeitos e estão profundamente marcadas pelas trajetórias sociais e experiências que cada grupo ou segmento social tem vivido.

Na obra Fisiologia do gosto, Brillart-Savarin ${ }^{9}$ aponta caminhos socioculturais de compreensão para tal questão. A história do gosto liga-se à história do cotidiano em suas sutilezas e às estruturas sociais, culturais e ideológicas. 
Igualmente nos faz pensar a questão do gosto o trabalho de Mintz, ${ }^{10}$ Sweetness and power, de 1985. Nesse estudo o autor analisa a história social da produção e do consumo do açúcar. Ao fazê-lo, revela-nos que, para além de uma explicação baseada na preferência inata pelo gosto doce ou pela simples imitação de uma classe abastada por uma mais humilde, o crescente aumento do consumo de açúcar, sobretudo entre a classe operária europeia do século XIX, está relacionado a uma busca por energia a ser convertida em trabalho e a uma associação com outros produtos - crescentes no mercado inglês - que passam a compor a dieta daquele grupo, como, por exemplo, o café e o chá. Nesse sentido, o autor observa uma interação entre interesses econômicos, poderes políticos, necessidades nutricionais e significados culturais, abstendo-se de uma explicação meramente causal do ponto de vista biológico.

A partir da argumentação de que a formação do gosto alimentar não se dá, exclusivamente, em nível individual, mas forma-se social e historicamente, passamos a analisar o processo do qual emerge um sistema alimentar, também chamado de "cozinhas", que dá sentido àquilo que se ingere, além de demarcar diferentes gostos. Maciel ${ }^{11} \mathrm{faz}$ algumas considerações:

As "cozinhas" representam uma complexificação do ato alimentar, que compreende a preparação, a combinação de elementos, a "composição" de um prato, ou seja, a transformação do alimento em comida ${ }^{11}$ (p.150).

O "gosto", este sentido através do qual o sabor é percebido, tem um papel fundamental na formação dessas cozinhas, afinal tanto a utilização das técnicas quanto a eleição dos elementos se darão conforme o gosto ou as preferências, ambos sensíveis no plano individual, mas inscritos num dado contexto sociocultural. Há uma importante crítica no sentido de não reduzir as cozinhas a um inventário ou a um repertório de ingredientes, nem convertê-las em fórmulas ou combinações de elementos cristalizadas no tempo e no espaço. As cozinhas devem ser reconhecidas acima de tudo na sua dinamicidade, ligada à identidade social; um projeto coletivo em constante reconstrução ${ }^{2}$ em que os aspectos convencionais ou tradicionais são perpassados por aspectos de inovação. Estas transformações acabam sendo absorvidas ou "digeridas" pela tradição, que, em patamares seguintes, criam novos modelos, adaptados aos modelos convencionais precedentes. Mediante de um processo histórico, uma série de elementos novos e referenciados na tradição funde-se no sentido de criar algo único capaz de demarcar identidades. Nessa perspectiva os ingredientes e técnicas estarão em constante relação com as preferências produzidas socialmente, articulando assim o gosto alimentar com a formação dessas cozinhas ou sistemas.

Tais afirmações tornam-se pertinentes na medida em que o que será definido como comida ou comestível dependerá de cada cultura ou segmento: quando se pensa, por exemplo, nas preferências por pratos mais calóricos entre camadas de trabalhadores braçais, isso não se deve a argumentos estritamente ligados a seu valor nutritivo, mas por representações sociais ligadas à força e à robustez. Da mesma forma, a observação do aumento do consumo de fast food entre jovens acaba por não 
ser pautada por perigos ou riscos à saúde, mas por significados compartilhados que definem o grupo e representam ideias de modernidade. Assim, já na primeira infância estamos imersos em critérios, parâmetros e classificações alimentares, o que é chamado "gosto".

É preciso mencionar a essa altura que tais formações e transformações não são dadas de forma consciente e utilitária, mas estão calcadas em interações de elementos imersos em dinâmicas sociais e históricas. Ao analisar os sentidos que as pessoas atribuem a certos alimentos, é fundamental um olhar atento para os diversos determinantes que compõem os "gostos". Estes significados, em última análise, podem ser diferentes mesmo dentro de uma mesma classe ou segmentos social. Em termos mais pragmáticos, ao se refletir sobre a prática profissional voltada tanto a indivíduos quanto a coletividades, consideramos que as escolhas alimentares não devem ser reduzidas a determinantes objetivos e de caráter utilitário.

\section{Um todo integrado - a noção de sistema alimentar}

De forma breve e sem a pretensão de esgotar o assunto, mas apenas de estimular novos debates, discorreremos sobre o que consideramos ser uma importante ferramenta teórico-metodológica para se pensar a alimentação contemporânea. Para tanto concordamos com Velho, ${ }^{12}$ que admite que as sociedades complexas contemporâneas envolvem categorias sociais distinguíveis em uma continuidade histórica; dotadas de uma heterogeneidade cultural que não está isolada, mas envolvida numa trama de relações sociais harmônicas ou não.

Para além do debate teórico-conceitual próprio do campo da antropologia, uma importante noção inicialmente trabalhada pelo sociólogo francês Jean-Pierre Poulain ${ }^{4}$ referente à alimentação vem merecendo destaque entre os pesquisadores sociais: a ideia de "sistema alimentar". O enfoque articula a análise das diversas atividades alimentares e percorre o fluxo do alimento sem desprezar, no entanto, os atores envolvidos. Assim os processos de plantação e colheita, produção, distribuição, preparo e consumo são percebidos de maneira interligada e a partir das relações existentes. Nesse modelo é preciso considerar que o alimento não se move ou se transforma sozinho; os processos de transformação, elaboração e consumo envolvem, acima de tudo, sujeitos. Dentre os diferentes atores, poderemos identificar produtores, profissionais de indústria, famílias, chefs de cozinha e todo um repertório de técnicas e representações que são próprias de cada grupo.

Em um contexto rural de produção de alimentos, nos processos de distribuição e na transformação em um prato a ser apreciado num restaurante, os sentidos atribuídos ao que se come e suas formas manifestas são variados, o que implica não somente dizer que o alimento percorre um fluxo em sua forma física, mas também que, nesse processo, ele passa a adquirir diferentes sentidos num modelo sistêmico que compreende perspectivas que envolvem o alimento e seus diferentes contextos locais e globais inter-relacionados. 
Contreras \& Garcial $^{3}$ pontuam que, embora de início esta concepção tenha sido fragmentada pelas diferentes tradições das ciências sociais (sociológica, antropológica), nos últimos anos tem-se produzido um "encontro transdisciplinar" capaz de trabalhar sob essa óptica, levando em conta a diversidade de definições, interpretações e ênfases atribuídas à noção. Esta noção, longe de ser consensual e da qual derivam diferentes desdobramentos como "redes alimentares" e "sistemas culinários", traz em si a noção de Mauss ${ }^{13}$ sobre "fato social total", ou seja, a ideia de que o ato alimentar está envolvido em vários níveis da realidade com instituições de diversas ordens (econômica, política, gênero, classe) e que é indispensável uma compreensão do fenômeno em sua totalidade, mesmo que a ênfase recaia sobre determinada atividade ou estágio específico de cada campo do conhecimento.

Cabe ainda destacar as contribuições da antropologia no sentido de incorporar à abordagem a questão dos significados envolvidos, chamando a atenção para o fato de que o ato alimentar é algo específico. Ou seja, mesmo em um contexto relativamente globalizado, em que se tenta encontrar a homogeneidade de práticas e de representações, a universalidade de comer ou se alimentar encontra-se com as especificidades de diferentes contextos que são demarcados por fatores socioculturais, econômicos e individuais. Estes devem ser levados em conta quando se pretende pensar sobre a comida e o comer. Não se pretende, contanto, determinar o enfoque ou os objetos dos demais campos, mas sim propor que estes trabalhem seus diferentes objetos com base nesse olhar sistêmico em que o alimento e o indivíduo não estão isolados, mas relacionados num fluxo dinâmico.

Longe de concluirmos esta reflexão, buscamos explorar o fato da alimentação como um tema que permite o diálogo entre as ciências que buscam dar conta desse fenômeno mediante diferentes ângulos. Enfatizar as ações simbólicas e específicas das diferentes atividades que compõem os sistemas alimentares, considerando as dinâmicas e os sentidos diante de cada contexto, tem sido tarefa da disciplina antropológica. Para tanto, o exercício de relativização e a valorização das diversidades constituem importantes contribuições da disciplina.

Enxergar o fenômeno da alimentação enquanto parte de um sistema integrado para além do simples ato de ingestão de alimentos pode enriquecer os campos que tratam dessa temática. Igualmente importante é o fato de estarmos lidando com conjuntos de símbolos que vão ser reutilizados pelas pessoas nas suas relações e atividades cotidianas, num processo que, além de fisiológico, é social. 


\section{Referências}

1. Lévi-Strauss C. O cru e o cozido. São Paulo, CosacNaify, 2004. 442 p. (Mitológicas, 1).

2. Maciel ME. Uma cozinha à Brasileira. Estud Hist (Rio J). 2004 jan/jun. (33):25-39.

3. Contreras J, Gracia M. Alimentação, sociedade e cultura. Rio de Janeiro: Fiocruz; 2011. 496 p.

4. Poulain J-P Sociologias da alimentação: os comedores e o espaço social alimentar. Florianópolis: UFSC; 2004. $311 \mathrm{p}$.

5. Fischler C. El (h)omnívoro: el gusto, la cocina y el cuerpo. Barcelona: Anagrama; 1995. 421 p.

6. Douglas M. Pureza e perigo. São Paulo: Editora Perspectiva; 1976. 215 p.

7. Flandrin J-L, Montanari M. História da alimentação. In: História da alimentação. 7 ed. São Paulo: Estação Liberdade; 2013. 885 p.

8. Bourdieu P. Gostos de classe e estilos de vida. In: Ortiz R (org.). Pierre Bourdieu: sociologia. São Paulo: Ática; 1983. p. 82-121.

9. Brillat-Savarin, Jean-Anthelme. Fisiologia do gosto. São Paulo: Cia. das Letras; 1995. 352 p.

10. Mintz SW. O poder amargo do açúcar. Recife: UFPE; 2003.

11. Maciel ME. Cultura e alimentação ou o que tem a ver os macaquinhos de Koshima com BrillatSavarin? Horiz antropol. 2001;7(16):145-56.

12. Velho G. Projeto, emoção e orientação em sociedades complexas. In: Individualismo e cultura: notas para uma antropologia da sociedade contemporânea. 7. ed. Rio de Janeiro: Jorge Zahar Ed., 2004, c1987. p. 13-27.

13. Mauss M. Ensaio sobre a dádiva, forma e razão da troca nas sociedades arcaicas. In: Sociologia e antropologia. São Paulo: Cosac \& Naify; 2003.

Recebido: $13 / 6 / 2013$

Aprovado: $15 / 8 / 2013$ 